\title{
TRANSFORMING A COMPETENCY MODEL TO ASSESSMENT ITEMS
}

\author{
Onjira Sitthisak, Lester Gilbert, and Hugh C Davis \\ Learning Technologies Group, School of Electronics and Computing Science \\ University of Southampton, Highfield \\ Southampton, SO17 1BJ, United Kingdom \\ \{os05r, lg3, hcd \}@ecs.soton.ac.uk
}

Keywords: competency, adaptive assessment, knowledge level

\begin{abstract}
The problem of comparing and matching different learners' knowledge arises when assessment systems use a one-dimensional numerical value to represent "knowledge level". Such assessment systems may measure inconsistently because they estimate this level differently and inadequately. The multi-dimensional competency model called COMpetence-Based learner knowledge for personalized Assessment (COMBA) is being developed to represent a learner's knowledge in a multi-dimensional vector space. The heart of this model is to treat knowledge, not as possession, but as a contextualized space of capability either actual or potential. The paper discusses the automatic generation of an assessment from the COMBA competency model as a "guide-on-the-side".
\end{abstract}

\section{INTRODUCTION}

In recent years, a variety of tools and learning environments have been created and installed in schools, universities, and organisations to support learning. Mostly these tools have been created to support e-learning content and collaborative learning activities like a virtual classroom (Koper and Specht, 2007). However, e-learning suggests not only new technologies for instruction but also new pedagogical approaches to enhance learning. One new pedagogical approach is machine-processable competency modelling. A competence model is introduced for storing, organizing and sharing learners' performance data in order to seek and interpret evidence for where the learners are in their learning, where they want to go, and how they can get there. Pedagogically effective and informed competency data is vital in any assessment system.

One of the desired outcomes of an assessment system is information about the learners' knowledge, identifying what learners can do by representing their current state of knowledge (Shepard, 2000). This information is collected and updated during the assessment process. Most assessment systems assume that knowledge is something that a learner possesses or fails to possess, and seek to estimate a learner's "knowledge level". As a result, such assessment systems may measure "knowledge level" inconsistently because they estimate this level differently, and inadequately because they use onedimensional numerical values (Sitthisak et al., 2007). The proposed solution is to consider the learners' "learned capability" instead of their "knowledge level", and to consider competencies and learned capabilities as a multidimensional space.

In the context of an adaptive assessment system, an assessment is part of the process of diagnosing the learner's competence. The key idea of an adaptive assessment system is that questions are selected by the computer to individually match the learner's competence (Way, 2005). The system's evaluation of the learner's competence is then used to guide the adaptation of the system (Aroyo et al., 2006). The system may skip over what learners have learned and find out what they should learn further. While an adaptive system may be more efficient for summative assessment, a system of adaptive formative assessment is likely to be of greater advantage to learners, since they would receive relevant, personalized feedback. Establishing adaptive formative assessment systems to support 
lifelong learning is extremely challenging and relies on introducing a competency model to the adaptive assessment. Our intention is not to promote a particular technological platform, but to demonstrate how a competency model can be applied to adaptive assessment.

In this paper, we introduce an advanced competency model named COMpetence-Based learner knowledge for personalized Assessment (COMBA). The COMBA model is represented in a multi-dimensional vector space, and we explore the assembly of competencies into a tree structure. We then consider the key task of adaptively generating assessments from such a competencies structure.

\section{THE MULTI-DIMENSIONAL COMBA MODEL}

Competence-based approaches in the field of elearning, institutional admissions, learners seeking courses, e-portfolios, job references, human resource management, and job descriptions are becoming more common. They appear to offer the opportunity to develop tools and services for data exchange, discovery, processing, analysis, and visualization to meet needs of learners, tutors, program managers, examination bodies, professional societies, employers, legislators, and so on. We suggest that a complete and coherent model of competencies would support storing, organizing and sharing of achieved, current, and intended performance data relating to all aspects of education and training in a persistent and standard way (Sitthisak et al., 2007). We have been developing a competency model, named COMBA, which is proposed for all domains where learning and teaching take place.

In the first stage of developing the model (Sitthisak et al., 2007), we conceptualised "competency" as involving a capability associated with a given subject matter content, requiring a proficiency level, and associated with evidence, any required tools, and a definition of the situation which contextualizes the competency. In the second stage of developing the model (Sitthisak et al., 2007), we implemented an exemplar UK Royal College of Nursing competency (UK Royal College of Nursing, 2005) reflecting relevant features of a learner's behaviour and knowledge that affected their learning and performance. An outcome of this implementation exposed a critical issue involving the expression of ethical practice in the COMBA model. One of the conceptions of competence for a nursing graduate is competence in ethical practice (Ramritu and Barnard, 2001) as well as the other characteristics of professional service delivery involving knowledge and psychomotor skill (Defloor et al., 2006). Hence, attitude, the way in which a learner exhibits their knowledge and skill, is included in the COMBA model, as illustrated in Figure 1.

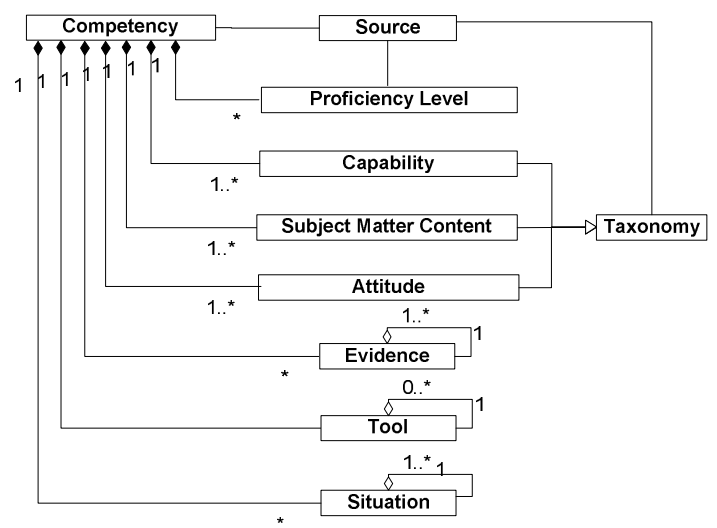

Figure 1: Competency model including attitude component

The COMBA model considers knowledge in the widest possible sense, and involves the following four major components: subject matter, capability, attitude, and context, along with metadata as illustrated in Figure 2.

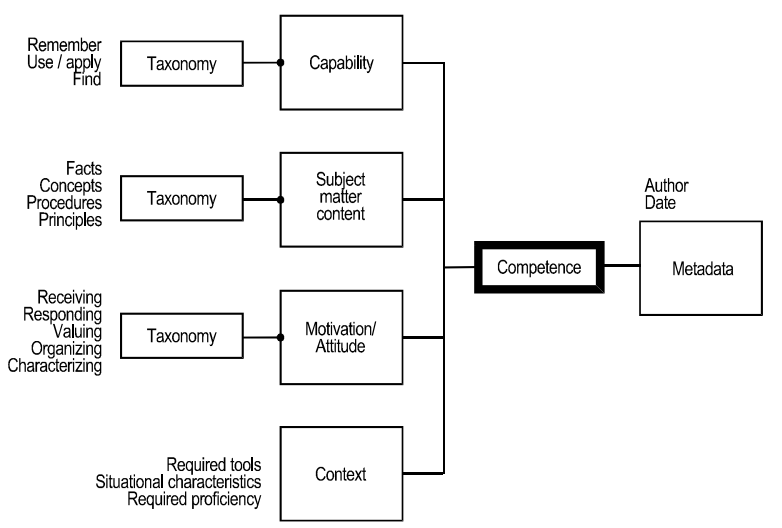

Figure 2: Individual competence model

The challenge of capturing and using knowledge starts with the problem of understanding its nature and representation. The failure of previous efforts to 'intelligently process knowledge' (e.g. intelligent tutoring systems) may be due to their pedagogically and cognitively inadequate characterization of this knowledge, and their simplistic assumptions that 
knowledge is some thing a learner possesses or fails to possess.

The heart of the COMBA model is to treat knowledge, not as possession, but as a contextualized multidimensional space of capability either actual or potential. Accordingly, the three important components of the COMBA model (capability, subject matter content, and attitude), which are referred from relevant taxonomies or ontologies, may be represented in a vector space as in Figure 3. The learned capability is the learner's required or observed behaviour, for example using Bloom's taxonomy (Bloom and Krathwohl, 1956). The subject matter content in Figure 3 is based on Merrill's analysis (Merrill, 1983), and attitude is based on a version of Krathwohl's taxonomy (Krathwohl and Anderson, 2002).

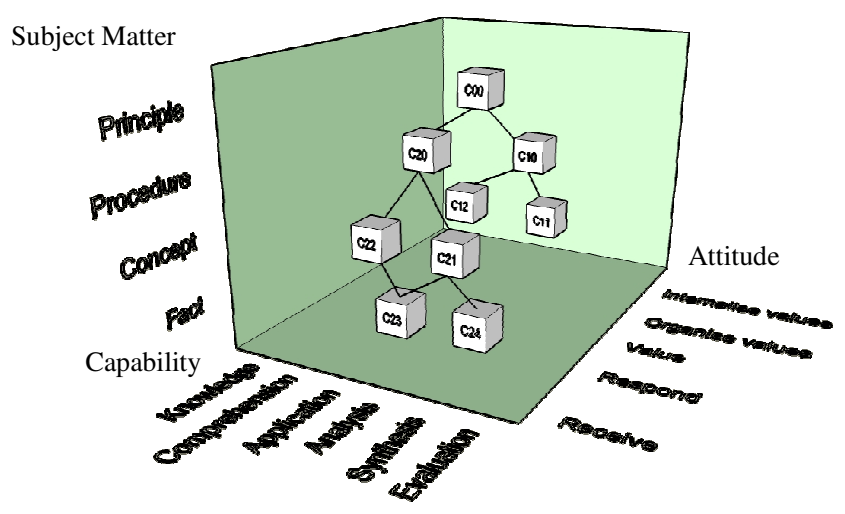

Figure 3: Multidimensional space of competency model

In this paper, we choose competencies from health care because they are amongst the most sophisticated and challenging to implement (Kunzmann, 2006). Table 1 represents some nursing competencies based on the multidimensional space of the COMBA model. For example, C00 (students are able to use and value ethical principles) comprises C10 (students are able to actively apply ethical principles) and $\mathrm{C} 20$ (students are able to actively use professional regulation). In order to achieve $\mathrm{C} 10$, students should be able to demonstrate client confidentiality respectfully $(\mathrm{C} 11)$, and to identify ethical issues sensitively $(\mathrm{C} 12)$. In order to achieve C20, students should be able to identify the limitations in their own practice (C22), and to considerately evaluate professional regulation (C21). There is a common competency for C21 and C22 which is $\mathrm{C} 23$ (students are able to recognize the need for referral willingly). In order to achieve C21, students should be able to recall relevant professional regulations willingly (C24). This shows that we can map effectively these more complicated competencies into the COMBA model. The subject matter, capability taxonomy, attitude taxonomy, and competence were ontologically represented based on the Simple Knowledge Organisation System (SKOS).

Table 1: Some example nursing competencies represented in the competency model

\begin{tabular}{llll}
\hline $\begin{array}{l}\text { Competency } \\
\text { No. }\end{array}$ & Capability & $\begin{array}{l}\text { Subject } \\
\text { Matter }\end{array}$ & Attitude \\
\hline C00 & Use & $\begin{array}{l}\text { Ethical } \\
\text { principles }\end{array}$ & Values \\
\hline C10 & Apply & Ethical issues & Actively \\
\hline C11 & Demonstrate & $\begin{array}{l}\text { Client } \\
\text { confidentiality }\end{array}$ & Respectfully \\
\hline C12 & Identify & Ethical Issues & Sensitively \\
\hline C20 & Use & $\begin{array}{l}\text { Professional } \\
\text { regulation }\end{array}$ & Actively \\
\hline C21 & Evaluate & $\begin{array}{l}\text { Professional } \\
\text { regulation }\end{array}$ & Considerately \\
\hline C22 & Identify & $\begin{array}{l}\text { Limitation in } \\
\text { own practice }\end{array}$ & Values \\
\hline C23 & Recognize & $\begin{array}{l}\text { Need for } \\
\text { referral }\end{array}$ & Willingly \\
\hline C24 & Recall & $\begin{array}{l}\text { Professional } \\
\text { regulations }\end{array}$ & Willingly \\
\hline
\end{tabular}

\section{THE COMPETENCY TREE}

Competencies are assembled into trees. A tree structure is a particular way of representing a structure in a graphical form (Johnson and Shneiderman, 1991). While the relationship between nodes is modelled as a family relation such as parent and child, there is no ordering of nodes on the same level, and this yields a tree structure rather than a hierarchy. It is assumed that all children of a defined competency are required in order to achieve proficiency for the parent. While the tree structure defines a top-down or bottom-up structure, it does not imply sequencing as might be implied in a hierarchy. For example, a competency tree may specify how to roll up the assessment for each competency throughout a competency tree without implying sequencing of assessments of same level competencies. So the issue of pedagogical sequencings are not considered at this stage by representing competencies as a tree structure instead of a hierarchy.

One of the advantages of a competence tree structure is that a tree structure separates the composition rule in the domain from other structural components. Hence, an application of the 
competency model, such as in adaptive assessment, may add other rules, perhaps based on pedagogical sequencing, in order to control the adaptation within the competency tree.

More technically, the COMBA model specifies the network of assembled competencies as a directed acyclic graph. In competency terms, Figure 4 implies that competency $\mathrm{COO}$ is decomposed into sub-competencies $C 10$ and $C 20$, such that $C 10$ and $C 20$ contribute to $C O O$. A node may have more than one parent, provided the parent is not a child of the node. Figure 4 shows a "forest" of two competency trees, where arrows represent parent-child relationships. A competency tree may specify common children for more than one node, or more than one origin node. For example, $C O O$ and $A$ represent different competencies that have certain competencies in common such as $C 22$.

It is expected that competency trees will be different for different communities and users. For example, a tree of nursing competencies from the UK Royal College of Nursing would have many points of difference from a similar tree from the Canadian Nursing Association. At a personal level, a student nurse may develop his or her own tree to reflect their own competencies, both achieved and to be attained.

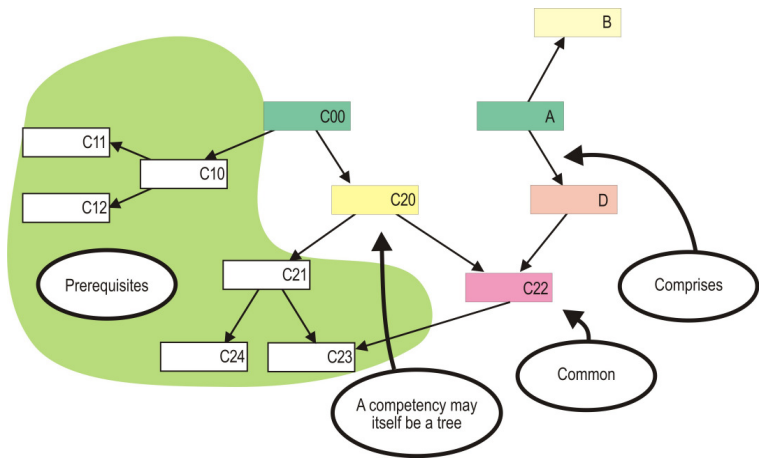

Figure 4: Competency tree

\section{GENERATING ASSESSMENT ITEMS FROM A COMPETENCY TREE}

Assessments may be categorized as formative, summative, or diagnostic (McMillan, 2006). Formative assessment provides prescriptive feedback to assist learners in achieving their competences (Rolfe and MaPherson, 1995). It is intended to help the learner deal with deficiencies in their understanding, knowledge, or competence. In contrast, summative assessment is generally given at the end of a period of learning to establish what knowledge, skills, and/or attitudes the learner has acquired over a period of time. It helps to establish whether learners have attained the competences required, and is not focussed on supporting learning. Diagnostic assessment is an in-depth assessment related to strengths and weaknesses in each skill area, which identifies priorities and needs (Sewell, 2004). It helps to determine what learners can already do within the goals of the curriculum. This paper focuses on formative and diagnostic assessment.

There are two problems of traditional formative assessment. First, learners are likely to need different kinds of formative assessment at different stages in their 'learning journeys' (Brown, 2006). Second, formative assessment usually only provides a list of the learner's deficiencies (Rolfe and MaPherson, 1995) without clearly specifying their boundaries. These problems are relieved by using an assessment tree suggested in this paper.

\subsection{Constructing an assessment item}

We assume an assessment which takes place in the context of the COMBA model. The competency tree might be used to drill down into component competencies for the tested competency, helping to define what to test and how to test it. An assessment for a competency often actually tests component competencies. For example, a paediatric nurse course (Nursing and Midwifery Council) may test knowledge of professional regulation by testing the learners' ability to demonstrate and evaluate understanding of professional regulation including the demonstration of a variety of specific skills and attitudes, as illustrated in Table 1.

A generic assessment item can be directly formulated from a competence specification by using the parameters of that competence: capability, subject matter content, attitude and other contexts such as tool and situation as the authoring question templates in Table 2. For example, the assessment corresponding to $\mathrm{C} 11$ might be something like "What information must be kept confidential in situation A?", or "Identify the information which doesn't need to be kept confidential in situation B", as illustrated in Table 3.

A formative assessment may contain items to test finer grained competencies. A competency tree can be used as a guide to assemble the necessary set of test items for assessing each competency. In this process, the competency tree is transformed to an assessment tree. An assessment tree consists of 
question nodes from Table 3, where each question node corresponds to a competency node, as illustrated in Figure 5.

Table 2: Question templates

\begin{tabular}{ll}
\hline No. & Question Templates \\
\hline $\mathrm{a}$ & {$[$ Capability $]+[$ Subject $]$} \\
$\mathrm{b}$ & [Capability $]+[$ Subject $]+[$ Situation $]$ \\
$\mathrm{c}$ & {$[$ Capability $+[$ Subject $]+[$ Attitude $]$} \\
$\mathrm{d}$ & {$[$ Subject $+[$ Situation $]$} \\
\hline
\end{tabular}

Table 3: Some example questions represented from the competencies

\begin{tabular}{cclc}
\hline $\begin{array}{c}\text { Compet- } \\
\text { ency No. }\end{array}$ & $\begin{array}{c}\text { Ques- } \\
\text { tion } \\
\text { No. }\end{array}$ & Question & $\begin{array}{c}\text { Temp- } \\
\text { late } \\
\text { No }\end{array}$ \\
\hline C00 & Q1 & $\begin{array}{l}\text { Identify the outcomes if } \\
\text { ethical principles were } \\
\text { not valued. }\end{array}$ & $\mathrm{c}$ \\
& Q2 & $\begin{array}{l}\text { List ethical principles. } \\
\text { What ethical principles } \\
\text { are involved [in situation } \\
\text { X]? }\end{array}$ & a \\
& Q3 & \\
\hline C10 & Q4 & $\begin{array}{l}\text { Identify the possible } \\
\text { outcomes if ethical issues } \\
\text { were not actively applied. }\end{array}$ & \\
& Q5 & $\begin{array}{l}\text { How would you apply } \\
\text { ethical issues [in situation } \\
\end{array}$ & b]? \\
& Q6 & $\begin{array}{l}\text { Define the specific } \\
\text { ethical issues [in situation } \\
\text { Z]. }\end{array}$ \\
& & b \\
\hline
\end{tabular}

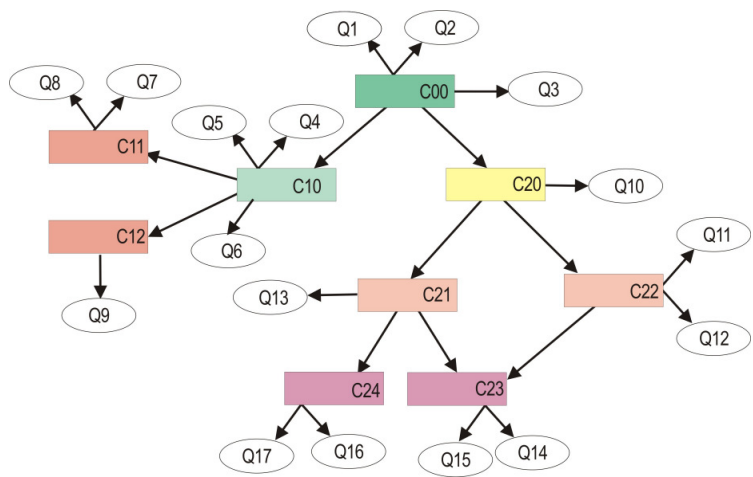

Figure 5: The group of questions based on a competency tree

Different organizations or communities of practice may have different processes and policies for assessment. By specifying a particular competency tree or sub-tree to be assessed, it is possible to align the assessment needed based on the needs of the organization or community of practice. Hence, the competency tree defines a standard way to specify explicitly the component competencies to be assessed, and provides a "guide on the side", automatically generating a set of general assessment items.

\subsection{Navigating assessment items on the competency tree}

There are a number of adaptive assessment methods and technologies that can be used to assess learners' strengths and weaknesses based on item-by-item and learner responses (Brusilovsky, 2001). These allow learners to be tested on materials at a level appropriate to their current understanding. Adaptive assessments change their behaviour and structure depending on the learners' responses and inferred abilities.

There are two major adaptation techniques; presentational adaptation and navigational adaptation (Brusilovsky, 2001). An adaptive system may apply these two techniques with questions. Traversing the competency tree may start at the leaf node or the root node depend on the objective of each application. As a result, a competency tree may be traversed, mapped, extended, visualized, and searched by a variety of applications and tools. For example, a competency tree may be used to specify how to roll up the assessments for each competency in order to personalize the assessment and match assessment items to the individual competences of each learner.

There is a set of possible assessment items associated with each competence node, as illustrated in Figure 5. Given a pruned competency tree (a tree whose remaining branches and leaves represent competencies not yet attained by a learner), an adaptive assessment system now needs to sequence the assessment items. Sequencing could be based upon pedagogical considerations, and arranged according to the taxonomies of subject matter content (Merrill, 1983), of capability (Bloom and Krathwohl, 1956), and so on. For example, an adaptive assessment system may start with assessment items at the lower level of the capability taxonomy and progress to the higher levels, in order to reach the boundary of the learner's understanding. On the other hand, sequencing could be based on the learner's preferences. Depending on the learner's answers, the next assessment item will be presented. This involves regenerating the sequence based on the learner's unfolding competences. The result of an adaptive assessment partitions the competency tree into "what the student can do" and "what the 
student is ready to learn" (Falmagne et al., 2003) and finding the boundaries of competence for the learner.

\section{CONCLUSIONS}

We have proposed the next generation of a competency model named COMBA to support adaptive assessment. The COMBA model includes "attitude", identified as a critical issue exposed by working with nursing competencies, as well as including subject matter domain knowledge, and learned capabilities. The multi-dimensional COMBA model represents competency in terms of a tree structure. Generating assessment items from the competency tree is illustrated. Then, an adaptive assessment involves constructing an item sequence which dynamically reconfigures as the learner's competency develops.

The benefits of a COMBA-enabled adaptive system are to help learners identify and diagnose their boundaries of their own competencies, understand them, and find out how to progress by comparing them with a given or ideal competency tree. Adaptive assessment involves the dynamic sequencing of assessment items derived from the COMBA competency tree depending on the learner's responses.

Learning is improved by allowing the learner to become familiar with the variety of assessment items that correspond to the variety of situations, tools, capabilities and subject matter content, expressed in a COMBA competence tree, of the domain of interest. We believe that a COMBA competency model is critical to successfully ensuring a pedagogic focus on learner and learning activities.

\section{REFERENCES}

Aroyo, L., Dolog, P., Houben, G. J., Kravcik, M., Nilsson, A. N. a. M. and Wild, F., 2006. Interoperability in Personalized Adaptive Learning. Education Technology and Society 9(2): 8-14.

Bloom, B. S. and Krathwohl, D. R., 1956. Taxonomy of educational objectives: The classification of educational goals by a committee of college and university examiners. New York, Longman.

Brown, S., 2006. Using Formative Assessment to promote student learning. from http://www.ldu.leeds.ac.uk/news/events/documents/Br ownPowerPoint.pdf.

Brusilovsky, P., 2001. Adaptive Educational hypermedia.
Defloor, T., Hecke, A. V., Verhaeghe, S., Gobert, M., Darras, E. and Grypdonck, M., 2006. The clinical nursing competences and their complexity in Belgian general hospitals. Journal of Advanced Nursing 56(6): 669-678.

Falmagne, J.-C., Cosyn, E., Doignon, J.-P. and Thiery, N., 2003. The Assessment of Knowledge, in Theory and in Practice. Integration of Knowledge Intensive MultiAgent Systems.

Johnson, B. and Shneiderman, B., 1991. Tree-Maps: a space-filling approach to the visualization of hierarchical information structures. Proceedings of the 2nd conference on Visualization '91, San Diego, California, IEEE Computer Society Press.

Koper, R. and Specht, M. (2007). TenCompetence: Lifelong Competence Development and Learning. Competencies in Organizational E-Learning: Concepts and Tools. M.-A. Sicilia, Idea Group.

Krathwohl, D. R. and Anderson, L., 2002. A revision of bloom's taxonomy: An overview. Theory into Practice 41(4): 212-218.

Kunzmann, C., 2006. Ontology-based Competence Management for Healthcare Training Planning: A Case Study. Proceeding of the International Conference on Knowledge Management, Austria.

McMillan, J. H., 2006. Classroom Assessment: Principles and Practice for Effective Instruction, Pearson Technology Group.

Merrill, M. D., 1983. Component Display Theory. Encyclopeadia of Educational Technology, from http://coe.sdsu.edu/eet/articles/cdt/index.htm.

Nursing and Midwifery Council. from http://www.nmcuk.org/aFrameDisplay.aspx? DocumentID=171.

Ramritu, P. L. and Barnard, A., 2001. New nurse graduates' understanding of competence. International nursing review.

Rolfe, I. and MaPherson, J., 1995. Formative assessment: how am I doing? Lacent 345(8953): 837-839.

Sewell, J., 2004. Diagnostic assessment within the Skills for Life strategy. 30th IAEA Conference, Philadelphia.

Shepard, L. A., 2000. The Role of Assessment in a Learning Culture. Journal Information for Educational Researcher 29(7): 4-14.

Sitthisak, O., Gilbert, L. and Davis, H. C., 2007. Towards a competency model for adaptive assessment to support lifelong learning. TENCompetence Workshop on Service Oriented Approaches and Lifelong Competence Development Infrastructures, Manchester, UK.

Sitthisak, O., Gilbert, L., Davis, H. C. and Gobbi, M., 2007. Adapting health care competencies to a formal competency model. The 7th IEEE International Conference on Advanced Learning Technologies, Niigata, Japan, IEEE Computer Society Press.

UK Royal College of Nursing. 2005. from http://www2.rcn.org.uk/cyp/resources/az_of_resources/competencies.

Way, W. D., 2005. Practical Questions in Introducing Computerized Adaptive Testing for K-12 Assessments. Research Report 05-03. 